\title{
Comparison of energy use efficiency of greenhouse and indoor plant factory system
}

\author{
Ying Zhang and M. Kacira \\ Department of Biosystems Engineering, The University of Arizona, Tucson, USA
}

\section{Summary}

Energy use efficiency in greenhouse and indoor plant factory system is greatly affected by outdoor climates, structure properties, operating conditions and product types. Energy use efficiency for two greenhouse cases and two indoor plant factory cases were compared in simulation with annual lettuce biomass yield and energy consumption including lighting, heating, and cooling for six geographic locations with different climates (Duluth, Minnesota; Seattle, Washington; Phoenix, Arizona; Miami, Florida; Abu Dhabi, UAE; and Riyadh, KSA). The energy balance of a greenhouse was simulated including Greenhouse 1 (GH_1) with a shading curtain $(50 \%$ shade percentage) deployed during high radiation seasons and Greenhouse 2 (GH_2) with a constant daily light integral level (DLI) of $15 \mathrm{~mol} \mathrm{~m}^{-2} \mathrm{~d}^{-1}$ achieved by supplemental lights and variable shading controls. In indoor plant factory model, two cases Indoor Plant Factory 1 (IPF_1) and Indoor Plant Factory 2 (IPF_2) were simulated with EnergyPlus, a building simulation program, with the DLIs of $13 \mathrm{~mol} \mathrm{~m}^{-2} \mathrm{~d}^{-1}$ and $15 \mathrm{~mol}$ $\mathbf{m}^{-2} \mathbf{d}^{-1}$ respectively. Using LED lights with high efficacy $\left(2.5 \mu \mathrm{mol} \mathrm{J}^{-1}\right)$, indoor plant factories were determined to be superior to greenhouses in cold climates with energy use efficiency as high as $0.13 \mathrm{~kg} \mathrm{kWh}^{-1}$ and $0.14 \mathrm{~kg} \mathrm{kWh}^{-1}$ respectively in Duluth and Seattle compared to greenhouse cases with $0.10 \mathrm{~kg} \mathrm{kWh}^{-1}$ and $0.11 \mathrm{~kg} \mathrm{kWh}^{-1}$ respectively. In hot climates greenhouses are significantly more efficient than indoor plant factories, with the highest energy use efficiency of $0.35 \mathrm{~kg} \mathrm{kWh}^{-1}$ in Miami. Parameters of indoor plant factory systems, including heating, ventilation, and air conditioning (HVAC) economizers, the number of tiers of production shelves, lettuce plant transpiration rate, and light efficacy, were evaluated for their impacts on energy usage and effectiveness for energy savings. Choosing LED lights with high efficacy was recommended to effectively reduce the electricity usage and to enhance energy use efficiency for indoor plant factories.

Keywords

economizer, energy consumption, HVAC system, lettuce, light efficacy, transpiration

\section{Introduction}

Indoor plant factory system is a plant production facility with sole-source electrical lighting for crop production and it is commonly designed with vertically stacked layers

\section{Significance of this study}

What is already known on this subject?

- Energy consumption in indoor plant factory system is significant. The energy use efficiency in greenhouse and indoor plant factory system are greatly affected by outdoor climates, structure properties, operating conditions and types of crop growing inside. It is important to assess the differences of energy use efficiency in these two systems and explore potential energy-saving strategies.

\section{What are the new findings?}

- The energy use efficiency of indoor plant factory system can be comparable to greenhouse system when operating in cold climate. However, in hot climate, greenhouses are significantly more efficient than indoor plant factories in terms of energy consumption. Plant transpiration and heat loads from sole source lighting system greatly affects the cooling loads and heating loads of HVAC system in indoor plant factory.

What is the expected impact on horticulture?

- Energy use efficiency for various greenhouses and indoor plant factory system types, parametric evaluations for six climates are reported. Integrating HVAC economizer and choosing high efficiency of LED lights are recommended to enhance energy use efficiency in indoor plant factory system.

to enhance land use efficiency. With a nearly air-tight and well-insulated structure, sole source lighting, and heating, ventilation, and air conditioning (HVAC) climate management system, indoor plant factories can be constructed in extreme environments to allow food production. There are various advantages of indoor farming including accelerating growth rate of crop, high land use efficiency and enable local food production with fresh produce for the consumers. Hydroponic cultivation enhances water use efficiency by using recirculating hydroponics systems and with recycling condensed water from the air condition systems to be used in the irrigation system. However, high start-up costs, high operating costs especially with electrical energy required for lighting, cooling and dehumidification, production most being limited to leafy greens, and environmental controls have been the bottlenecks (Kalantari et al., 2018). Improved system designs, environmental control strategies, new crop varieties, automation and robotics must be considered for profitable operations.

Energy consumption is one of the major costs for running an indoor plant factory. Lighting, HVAC system, fans, pumps, and automation system all require a large amount 
of electricity to operate, especially for lighting and HVAC system. Therefore, it is often argued that indoor plant factories are less efficient than greenhouses. The comparison of energy consumption and profitability has been conducted for different scenarios. Harbick and Albright (2016) studied annual energy consumption of greenhouses and indoor plant factories for four cases: a greenhouse model with and without winter ventilation for humidity and condensation control and an indoor plant factory model with and without economizer control for energy saving. Economizer is an air conditioning cycle that takes advantage of the free cooling capacity of outdoor air to reduce the mechanical cooling requirement of a building. The results showed that the energy consumption in indoor plant factories are significantly higher compared to the greenhouses. Eaves and Eaves (2018) reported the results of a simulation of the profitability of growing lettuce in an indoor plant factory and a greenhouse with supplemental lighting located near Quebec City. For electricity usage, it was found that an indoor plant factory used more electricity for lighting and indoor climate control (with forced ventilation system and natural gas heaters), while more land was required to operate a greenhouse. Graamans et al. (2018) evaluated energy use efficiency of indoor plant factories and greenhouses for different locations. The study indicated that although indoor plant factories required more purchased energy to produce $1 \mathrm{~kg}$ dry weight of lettuce compared to greenhouse cases, in terms of energy efficiency based on all energy used, plant factories surpassed even the most efficient greenhouse. Energy consumption of greenhouses and indoor plant factories varies from case to case. For indoor plant factory, further studies are needed to analyze how energy consumption and crop production respond to the changes of system parameters, such as operational characteristics, crop types, outdoor climate conditions, and building construction and insulation.

In this study, the energy use efficiency of two greenhouse cases and two indoor plant factory cases for lettuce production were compared with energy consumption for lighting, heating, and cooling and lettuce production. Energy use efficiency $\left(\mathrm{kg} \mathrm{kWh}^{-1}\right)$ was defined as fresh weight kilograms of crop produced per kilowatt-hour of energy. Six locations under different climates were selected to analyze how outdoor climates affect the total electricity usage, lettuce production and heating and cooling loads in both production systems. The results were further analyzed with one indoor plant factory by parametric analysis, including total tiers (1 tier, 5 tiers and 11 tiers), lettuce transpiration rate $(21.5,43$ and $\left.64.5 \mathrm{~mL} \mathrm{head}^{-1} \mathrm{~d}^{-1}\right)$, light efficacy $\left(2,2.5\right.$ and $\left.3 \mu \mathrm{mol} \mathrm{J}^{-1}\right)$, integrating an economizer to HVAC system to mix outdoor suitable air with returned air in the HVAC system to reduce cooling loads.

\section{Materials and methods}

\section{Mathematical models}

1. Energy balance of greenhouses. The energy balance of a greenhouse was analyzed. The air inside the greenhouse was treated as a control volume, with a boundary at the glazing, the ground, lettuce canopy surfaces, and any vents and gaps in the structure. The forms of energy transfer in the greenhouse includes conduction, convection, radiation, latent heat, and infiltration. The air in the greenhouse was assumed to be well mixed and no spatial variation in air temperature. The rate of change of energy storage was ignored. The energy balance equation is represented by the following equation
(Mesmoudi et al., 2010; Graamans et al., 2017):

$$
Q_{R}-Q_{F}-Q_{S}-Q_{P}+Q_{L}-Q_{I}-Q_{C}+Q_{H}=0
$$

where $Q_{R}$ is the heat transfer by solar radiation (W), $Q_{F}$ is the heat transfer via conduction and convection across the glazing due to the temperature difference between the outside and inside air (W), $Q_{S}$ is the heat transfer from or to the ground (W), $Q_{P}$ is the latent heat transfer due to plant transpiration $(\mathrm{W}), Q_{L}$ is the radiation and heat transfer from supplemental lighting $(\mathrm{W}), Q_{I}$ is the heat transfer due to air exchange (W), $Q_{C}$ is the heat removed by a fan and pad evaporative cooling system (W), and $Q_{H}$ is the heat added to the greenhouse from a heating unit (W).

The amount of radiation transmitted, reflected, and absorbed by the greenhouse wall depends on the glazing and shading material properties. In this study, the glazing was assumed to be double layer polycarbonate with infrared additives, which has light transmission of $78 \%$ and thermal transmittance of $3 \mathrm{~W} \mathrm{~m}^{-2}{ }^{\circ} \mathrm{C}$ (Sanford, 2009). Shading levels change from 0 to $100 \%$ when daily light integral (DLI) is under control. DLI is the amount of photosynthetically active radiation (PAR) received each day and it is expressed as moles of light per square meter per day $\left(\mathrm{mol} \mathrm{m}^{-2} \mathrm{~d}^{-1}\right)$. The variable $Q_{R}$ was:

$$
Q_{R}=\tau_{c} S I_{s r} A_{f}
$$

where $\tau_{c}$ was the light transmissivity of the greenhouse glazing, $S$ was the shading level (0-100\%), $I_{s r}$ was the global horizontal solar radiation energy received outside of the greenhouse ( $\mathrm{W} \mathrm{m}^{-2}$ ), and $A_{f}$ was the total floor area of the greenhouse $\left(\mathrm{m}^{2}\right)$.

The heat loss by radiation, conduction and convection was calculated as:

$$
Q_{F}=U A_{c}\left(T_{i}-T_{o}\right)
$$

where $\mathrm{U}$ was the overall heat transfer coefficient $\left(\mathrm{W} \mathrm{m}^{-2}{ }^{\circ} \mathrm{C}\right)$, $A_{c}$ was the total area of the greenhouse cover $\left(\mathrm{m}^{-2}\right), T_{i}$ was the air temperature inside the greenhouse $\left({ }^{\circ} \mathrm{C}\right)$, and $T_{o}$ was the outside air temperature $\left({ }^{\circ} \mathrm{C}\right)$.

The heat flux exchange at ground surface was determined by:

$$
Q_{G}=K_{s}\left(T_{s 4}-T_{s 20}\right) A_{g} / L
$$

where $K_{s}$ was soil thermal conductivity coefficient $\left(\mathrm{W} \mathrm{m}^{-1}{ }^{\circ} \mathrm{C}^{-1}\right)$, $T_{s 4}$ and $T_{s 20}$ were the temperature of soil at $4 \mathrm{~cm}$ depth and $20 \mathrm{~cm}$ depth respectively, $A_{g}$ was the total ground area $\left(\mathrm{m}^{2}\right)$, and $L$ was the distance between two measurements $(0.16 \mathrm{~m})$.

Heat exchanges due to air exchanges in one hour was calculated in the following formula:

$$
Q_{I}=0.373 \times A C H \times V \times\left(T_{i}-T_{o}\right)
$$

where 0.373 was the constant representing the heat content of air $\left(\mathrm{W} \mathrm{m}^{-3}{ }^{\circ} \mathrm{C}^{-1}\right)$, ACH was the number of natural air exchanges per hour $\left(\mathrm{h}^{-1}\right)$. For a greenhouse with new construction and double layer plastic film, $A C H$ can vary from $0.5-1 \mathrm{~h}^{-1}$ and it was set at $0.5 \mathrm{~h}^{-1}$ for the studied greenhouse, $V$ was greenhouse volume $\left(\mathrm{m}^{3}\right)$.

2. Energy balance at crop canopies. At a crop canopy, a large portion of incoming solar radiation absorbed by a leaf is converted to the thermal energy of leaves. Energy absorbed at leaf surfaces can be dissipated by radiation emission, heat convection, and transpiration (Defraeye et al., 2013). Plant transpiration contributes significant to plants' physiological functions. By transpiring water vapor from leaves into the atmosphere, it increases the humidity in the 
air and reduces the leaf temperature. During the transpiration process, heat from the surrounding atmosphere is taken to remain the leaf in equilibrium, resulting in a reduction in surrounding air temperature (Gupta et al., 2018). The energy balance equation at crop canopies was expressed as:

$$
R_{n}-H-\lambda E=0
$$

where $R_{n}$ was the net radiation effectively absorbed by lettuce crop (W m $\left.{ }^{-2}\right), H$ was the convective sensible heat transfer $\left(\mathrm{W} \mathrm{m^{-2 }}\right)$, and $\lambda E$ was the latent heat transfer $\left(\mathrm{W} \mathrm{m}^{-2}\right)$. It was assumed that $5 \%$ of the total incoming radiation was reflected at leaf surfaces and the rest of radiation received at leaf surfaces is absorbed (Graamans et al., 2017).

The latent heat of the lettuce crop was determined using the Penman-Monteith equation (Pollet et al., 2000):

$$
\begin{aligned}
& Q_{P}=\lambda E A_{p}=\left(\frac{s\left(R_{n}-F\right)}{s+\gamma^{*}}+\frac{\left(\rho c_{p} D / r_{b}\right)}{s+\gamma^{*}}\right) A_{p} \\
& \gamma^{*}=\gamma\left(1+\frac{r_{c}}{r_{b}}\right)
\end{aligned}
$$

where $\lambda$ was the latent heat of vaporization $\left(2,260,000 \mathrm{~J} \mathrm{~kg}^{-1}\right)$, $A_{p}$ was the production area $\left(\mathrm{m}^{-2}\right), s$ was the slope of the saturation vapor pressure-temperature curve $\left(\mathrm{g} \mathrm{m}^{-3} \mathrm{~K}^{-1}\right), F$ was the soil flux ( $\mathrm{W} \mathrm{m}^{-2}$ ); $\rho$ was the density of the air $(1.204$ $\left.\mathrm{kg} \mathrm{m}^{-3}\right), c_{p}$ was the specific heat of the air $\left(1,010 \mathrm{~J} \mathrm{~kg}^{-1} \mathrm{~K}^{-1}\right), D$ was the vapor pressure deficit $\left(\mathrm{g} \mathrm{m}^{-2}\right), \gamma^{*}$ is calculated from the psychrometric constant $\gamma\left(\mathrm{Pa}^{\circ} \mathrm{C}^{-1}\right), r_{c}$ was the crop resistance $\left(\mathrm{s} \mathrm{m}^{-1}\right)$, and $r_{b}$ was the aerodynamic resistance of the crop $\left(\mathrm{s} \mathrm{m}^{-1}\right)$. In this study, the leaf area density of the crop canopy was assumed as 4.7 , the mean leaf diameter $(I)$ was set at $0.14 \mathrm{~m}$, the uninhibited air current speed at leaf surfaces $\left(u_{\infty}\right)$ was assumed as $0.3 \mathrm{~m} \mathrm{~s}^{-1}$. These parameters affect $r_{b}$ and $r_{c}$ for gas and water exchange (Pollet et al., 2000; Graamans et al., 2018):

$$
\begin{aligned}
& r_{b}=350 \times\left(\frac{l}{u_{\infty}}\right)^{0.5} \times L A I^{-1} \\
& r_{c}=\frac{r_{b}}{2 L A I}
\end{aligned}
$$

3. Indoor plant factory model. The energy simulation in indoor plant factories was predicted by a simulation software EnergyPlus. The indoor plant factory geometry was designed in Sketchup and imported into EnergyPlus to define building features. The energy balance of an indoor plant factory includes all energy flows through its envelope and sources and sinks of energy inside the building. The heat flows can be arranged into five categories showing below:

$$
Q_{F}+Q_{L}+Q_{P}+Q_{C}+Q_{H}=0
$$

where $Q_{F}$ is the heat transfer through the building, including the heat flow due to conduction and convection and the heat gain from solar heating of the opaque building envelope (W), $Q_{L}$ is the internal heat outputs from the sole source lighting (W), $Q_{P}$ is the latent heat transfer due to plant transpiration (W), $Q_{C}$ and $Q_{H}$ is the heat removed/added to the building envelope for cooling or heating by heating, ventilation, and air-conditioning system to maintain the desired room temperature $\left(\mathrm{W} \mathrm{m}^{-2}\right)$. In this study, only the energy released from LED lights was considered as a single source of internal heat gain. Daily water consumption of lettuce in a plant factory was measured. The transpiration rate of lettuce was set at
$43 \mathrm{~mL}$ head $^{-1} \mathrm{~d}^{-1}$ according to the results of the experimental study.

4. Lettuce growth model. In this study, a dynamic lettuce growth model was used as a function of the incident photosynthetically active radiation, the ambient air temperature, and carbon dioxide concentration to predict the growth of a lettuce crop (Van Henten, 1994). Lettuce growth models have been developed under different climate conditions for certain varieties. Okada et al. (2018) compared four lettuce crop models including Shimizu et al. (2008), Both (2003), Pearson et al. (1997), and Van Henten (1994) for greenhouse production. The yields of lettuce predicted by the four models were compared to the experimental data reported by Kacira et al. (2017) for final fresh weights under the same growing weather conditions of Tucson, Arizona. The Van Henten model was determined as the best model among four models to predict lettuce growth with acceptable accuracy compared to measured values reported by Kacira et al. (2017). In the Van Henten model, the total dry weight of lettuce crop includes non-structural dry weight (e.g., glucose, sucrose, and starch) and structural dry weight (e.g., cell walls and cytoplasm). The accumulation of structural dry weight $\left(X_{\text {sdw }}\right)$ and the non-structural dry weight of lettuces $\left(X_{n s d w}\right)$ on a square-meter soil basis at a given time was described as follows:

$$
\begin{aligned}
& \frac{d X_{n s d w}}{d t}=c_{\alpha} f_{p h o t}-r_{g r} X_{s d w}-f_{r e s p}-\frac{1-c_{\beta}}{c_{\beta}} r_{g r} X_{s d w} \\
& \frac{d X_{s d w}}{d t}=r_{g r} X_{s d w}
\end{aligned}
$$

where $f_{\text {phot }}$ was the gross canopy photosynthesis $\left(\mathrm{g} \mathrm{m}^{-2} \mathrm{~s}^{-1}\right)$, $c_{\alpha}$ was the factor that converts assimilated $\mathrm{CO}_{2}$ into sugar, which was the ratio of the molecular weights of $\mathrm{CH}_{2} \mathrm{O}$ and $\mathrm{CO}_{2}, r_{g r}$ was the specific growth rate that describes the transformation rate of non-structural dry weight to structural dry weight $\left(\mathrm{s}^{-1}\right), f_{\text {resp }}$ was the maintenance respiration $\left(\mathrm{g} \mathrm{m}^{-2} \mathrm{~s}^{-1}\right)$, and $c_{\beta}$ was the factor that indicates the respiratory and synthesis losses of non-structural material due to growth. Environmental parameters, including photosynthetically active radiation (PAR) intensity, air temperature, and $\mathrm{CO}_{2}$ concentration are the main factors that affect the growth rate of lettuce crop. In this study, hourly climatic data from EnergyPlus weather files were imported to the model to predict hourly accumulation of dry weight and fresh weight. A value of 0.75 was used for the ratio of structural dry weight to total dry weight. According to the data of lettuce biomass yield provided by an indoor farm (Urban Agriculture Vertical Farm at the University of Arizona), the ratio of dry weight of shoot to total dry weight and fresh weight was 0.92 and 0.03 , respectively. The initial dry weight of lettuce seedlings normalized by growing area was set at $7.2 \mathrm{~g} \mathrm{~m}^{-2}$ with a cropping density of 48 head m$^{-2}$.

\section{Case comparison}

In this study, the energy use efficiency for heating and cooling in greenhouses and indoor plant factories under six outdoor climates were compared, including two greenhouse cases and two indoor plant factory cases. All cases had the same footprint of $1,891 \mathrm{~m}^{2}$ (31 $\mathrm{m}$ width and $61 \mathrm{~m}$ length), which is a typical area of a small industrial warehouse in the US. Lettuce was growing at a continuous mode with an average crop spacing of 48 head $\mathrm{m}^{-2}$.

The total number of growing cycles per year was predicted by the lettuce growth model. The total number of days per 
cycle was calculated from transplanting to harvest when lettuces reached to $150 \mathrm{~g}$ fresh weight. The energy use efficiency was evaluated as:

$$
E_{e}=\frac{\text { Total kilograms of lettuce per year }}{\text { Total electricity use per year for }}
$$

Four cities in the US (Liu et al., 2017) and two cities in the Middle East representing six typical climates were selected to study how outdoor climates affect energy demands for heating and cooling. For greenhouse energy balance analysis, hourly outdoor climatic data were obtained from EnergyPlus weather files including dry bulb temperature, dew point temperature, relative humidity, and global horizontal radiation. Dry bulb temperature data were used to calculate the hourly temperature gradient of inside and outside air. Hourly value of vapor pressure deficit was calculated with dew point temperature and relative humidity data, which affected the transpiration rate of lettuce crop. Global horizontal radiation data was used to determine the amount of solar radiation received hourly. The cities and their climate classification are Duluth, Minnesota (very cold); Phoenix, Arizona (hot and dry); Seattle, Washington (cold moderate); Miami, Florida (hot and humid); Abu Dhabi, UAE (extreme hot); and Riyadh, KSA (extreme hot and dry). The outdoor monthly DLIs and relative humidity were plotted against outdoor monthly air temperature in Figure 1.

The greenhouses studied were assumed as 8-span ridgeand-furrow greenhouses with double layer polycarbonate sheets covered. The ratio of growing area to floor area was $90 \%$. With an insulated foundation installed, the exchange of heat at ground was ignored. The light transmittance of the covering material was $78 \%$. The setpoint air temperature for daytime and nighttime were $24^{\circ} \mathrm{C}$ and $19^{\circ} \mathrm{C}$, respectively. Cooling was achieved by a pad-and-fan evaporative cooling system. The amount of energy required for heating would be same based on heating method selected. With energy usage in $\mathrm{kWh}$ reported, heating cost for heating with fossil fuels can be converted with energy content and energy costs. In each span of the greenhouses one gable attic fan and two exhausted fans installed can achieve the maximum volumetric flow rate of $13,932 \mathrm{~m}^{3} \mathrm{~h}^{-1}$ (1,740 watts per hour) to bring in outdoor air through the cooling pad. A water pump (5,966 watts per hour) was sized for the system to circulate $73 \mathrm{~m}^{3}$ of water per hour for evaporative cooling. The efficiency of the cooling and heating systems were assumed as $80 \%$. The $\mathrm{CO}_{2}$ concentration in the greenhouse was set at $400 \mathrm{ppm}$. The effect of transpiration of lettuce crop was simulated with the lettuce transpiration model and the average transpiration rate of one head of lettuce was $90 \mathrm{~mL} \mathrm{~d}^{-1}$ in GH_1 and GH_2. Natural solar energy was the exclusive source of photosynthetically active radiation (PAR) in Greenhouse 1 (GH_1). Shading curtains with $50 \%$ of shade percentage were deployed during high radiation period in a year to maintain the DLIs inside greenhouse within $30 \mathrm{~mol} \mathrm{~m}^{-2} \mathrm{~d}^{-1}$. The shading periods for six locations are: May 1 to August 15 for Duluth and Seattle, March 15 to October 15 for Miami and Phoenix, February 15 to October 31 for Abu Dhabi and Riyadh. The DLIs inside Greenhouse 2 (GH_2) was controlled and maintained at $15 \mathrm{~mol} \mathrm{~m}^{-2} \mathrm{~d}^{-1}$. Supplemental lighting with LED lights (efficacy $=2.5 \mu \mathrm{mol} \mathrm{J}{ }^{-1}$ ) was used in Greenhouse 2 during the time period with low levels of solar radiation. If the DLI in Greenhouse 2 in a day was less than $15 \mathrm{~mol} \mathrm{~m}^{-2} \mathrm{~d}^{-1}$, supplemental lighting was set on with a photosynthetic photon flux
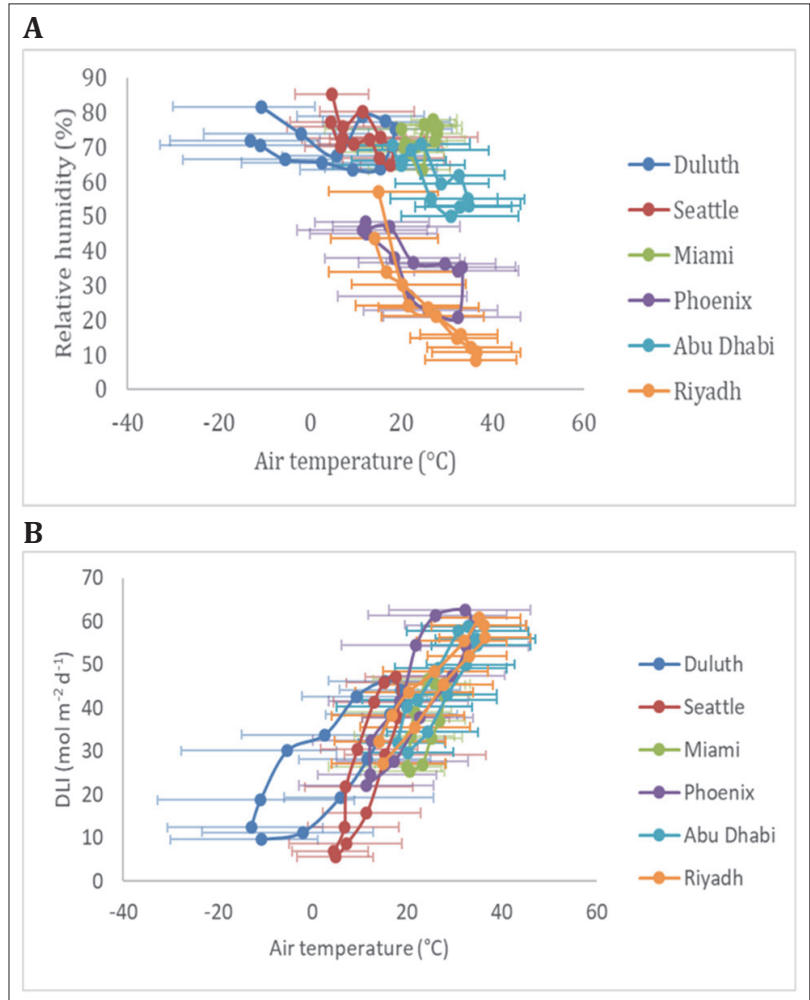

FIGURE 1. Typical climate zones with (a) Average daily light integrals per month $\left(\mathrm{mol} \mathrm{m}^{-2} \mathrm{~d}^{-1}\right)$ and monthly average, minimum and maximum air temperatures $\left({ }^{\circ} \mathrm{C}\right)$ and (b) Average relative humidity (\%) per month and monthly average, minimum and maximum air temperature.

density of $250 \mu \mathrm{mol} \mathrm{m}^{-2} \mathrm{~s}^{-1}$ after sunset until DLI had reached to $15 \mathrm{~mol} \mathrm{~m}^{-2} \mathrm{~d}^{-1}$.

The indoor plant factory model had a growing area to floor area ratio of $72 \%$. The roof and walls of the building were constructed with sandwich panels with aluminum and fiberglass insulation. The total thermal conductivity of the roof and outside walls are $0.21 \mathrm{~W} \mathrm{~m}^{-2} \mathrm{~K}^{-1}$ and $0.48 \mathrm{~W}$ $\mathrm{m}^{-2} \mathrm{~K}^{-1}$ respectively. The LED lights in the model had a light efficacy of $2.5 \mu \mathrm{mol} \mathrm{J}{ }^{-1}$. The LED lights were assumed as the only source of internal heat gains in the indoor plant factory model. The total power input was converted into PAR (63\%), long-wave radiation (2\%), and convection heat loss (35\%). Both two cases had a photoperiod of 16 hours and the same daytime and nighttime temperature as greenhouse cases $\left(24 / 19^{\circ} \mathrm{C}\right)$. The targeted DLI was 13 and $15 \mathrm{~mol} \mathrm{~m}^{-2} \mathrm{~d}^{-1}$ in Indoor Plant Factory 1 (IPF_1) and Indoor Plant Factory 2 (IPF_2) respectively. The coefficient of performance (COP) of the HVAC system for cooling was assumed at 3.45 and the efficiency of heating system was $80 \%$. Daily water consumption of lettuce in a plant factory was measured. The transpiration rate of lettuce was set at $43 \mathrm{~mL}_{\text {head }} \mathrm{d}^{-1}$ according to the results of the experimental study. The key model parameters for the compared cases are listed in Table 1.

\section{Results and discussion}

\section{Model validation}

The studied greenhouse was located at Tucson, Arizona with North-South orientation. It was one of the even-span contiguous greenhouses and covered with air-inflated, double-polycarbonate film glazing (transmittance $=75 \%$ ) with 


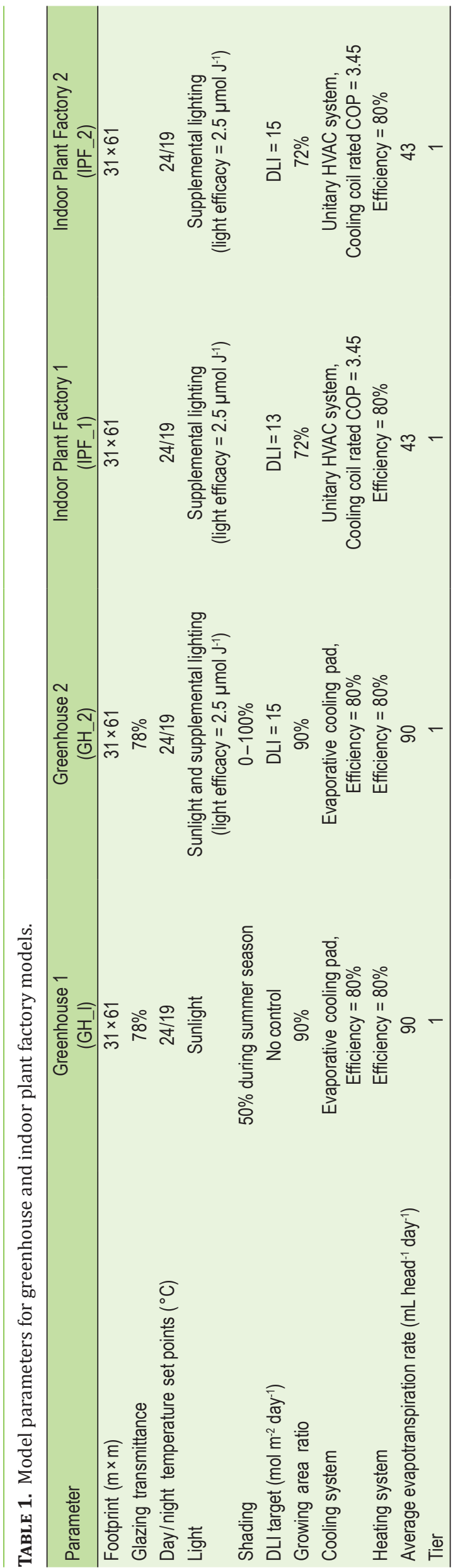

$14.6 \mathrm{~m}$ length, $7.32 \mathrm{~m}$ width, $2.59 \mathrm{~m}$ side wall height, and $4.42 \mathrm{~m}$ eaves height. Shading curtains were deployed to reduce $50 \%$ of total solar radiation received during the summer season. Indoor climate was controlled by a pad-and-fan evaporative cooling system and a natural gas fired heater. The indoor air temperature set points were $25.6^{\circ} \mathrm{C}$ and $18.9^{\circ} \mathrm{C}$ for daytime and nighttime. The cooling system was equipped with three fans (one gable attic fan: single phase with volumetric flow rate of $628.6 \mathrm{~m}^{3} \mathrm{~h}^{-1}$ and two large exhausted fans: single phase with volumetric flow rate of $2930.8 \mathrm{~m}^{3} \mathrm{~h}^{-1}$ ) with 3 -stage setpoints $\left(25.6^{\circ} \mathrm{C}, 26^{\circ} \mathrm{C}\right.$, and $\left.27.2^{\circ} \mathrm{C}\right)$. Lettuces were growing in the greenhouse with a growing area to floor area ratio of $44 \%$. The heat fluxes exchanged at ground were determined with soil thermal conductivity of $1.15 \mathrm{~W} \mathrm{~m}^{-1}{ }^{\circ} \mathrm{C}^{-1}$.

Hourly indoor air temperature data in three continuous days in August in a greenhouse were collected and compared to the predicted air temperatures from simulation. The difference between measured air temperatures and predicted air temperatures was compared by computing the areas under the curve (AUC) with the trapezoidal rule. The closer AUC, the better accuracy the model is. The ratio of the difference of AUC for simulation and prediction to the AUC for measurement was $3.86 \%$.

The energy simulation via EnergyPlus for indoor plant factories was validated at a small indoor plant factory (Urban Agriculture Vertical Farm at the University of Arizona), located at Tucson, Arizona. The vertical farm had two identical growing rooms with the dimension of $6.03 \mathrm{~m}$ length, $3.71 \mathrm{~m}$ width, and $3.91 \mathrm{~m}$ height for one room. Each room equipped with two production racks, a heat pump air conditioner, LED lights with a light efficacy of 1.6, one air pump, and two water pumps. The heat pump had a coefficient of performance (COP) of 3.45 , which measures how much energy output is produced for one unit of energy input. The LED lights, water pumps, air pumps, and lettuce crop in the vertical farm created internal heat sink/source in the building envelope. The forms of heat flux include long-wave radiation, photosynthetically active radiation (PAR), sensible heat, and latent heat. It was assumed that the energy consumed by LED lights were converted to PAR (36\%), long-wave radiation (10\%), and sensible heat (54\%) (Liu et al., 2017). For air pump and water pumps, it was assumed that heat was lost as $20 \%$ by radiation and $80 \%$ by convection (Hosni et al., 1999). Lettuce transpiration effect (lettuce transpiration rate $=43 \mathrm{~mL} \mathrm{head}^{-1} \mathrm{~d}^{-1}$ ) was included by applying the energy balance equation at lettuce canopy. The internal heat gains in the building envelope was adjusted according the radiation flux, the sensible heat flux, and the latent heat flux exchange at the canopy. The air temperature set points are $23^{\circ} \mathrm{C} / 19^{\circ} \mathrm{C}$ for daytime/nighttime. Two cycles of lettuce production were recorded for the energy consumption of heat pump (Cycle 1: 4/3/2018 - 5/1/2018 and Cycle 2: 5/23/2018 $6 / 20 / 2018$ ). Each cycle is of 28 days growing lettuces from transplanting to harvest, with a total usage of $770 \mathrm{kWh}$ and 1,092.2 kWh, respectively. Percent error between predicted and measured electrical energy use was used for model validation. Thus, compared to the predicted values from simulation $(752.5 \mathrm{kWh}$ and $935.9 \mathrm{kWh})$, the errors are $-2.2 \%$ and $-14.31 \%$, respectively.

\section{Case comparison}

1. Greenhouse inside air temperatures. The monthly average air temperatures inside greenhouses varied with outdoor climates. The outdoor climates greatly affect the cooling capacity and efficiency of pad-and-fan evaporative cooling 


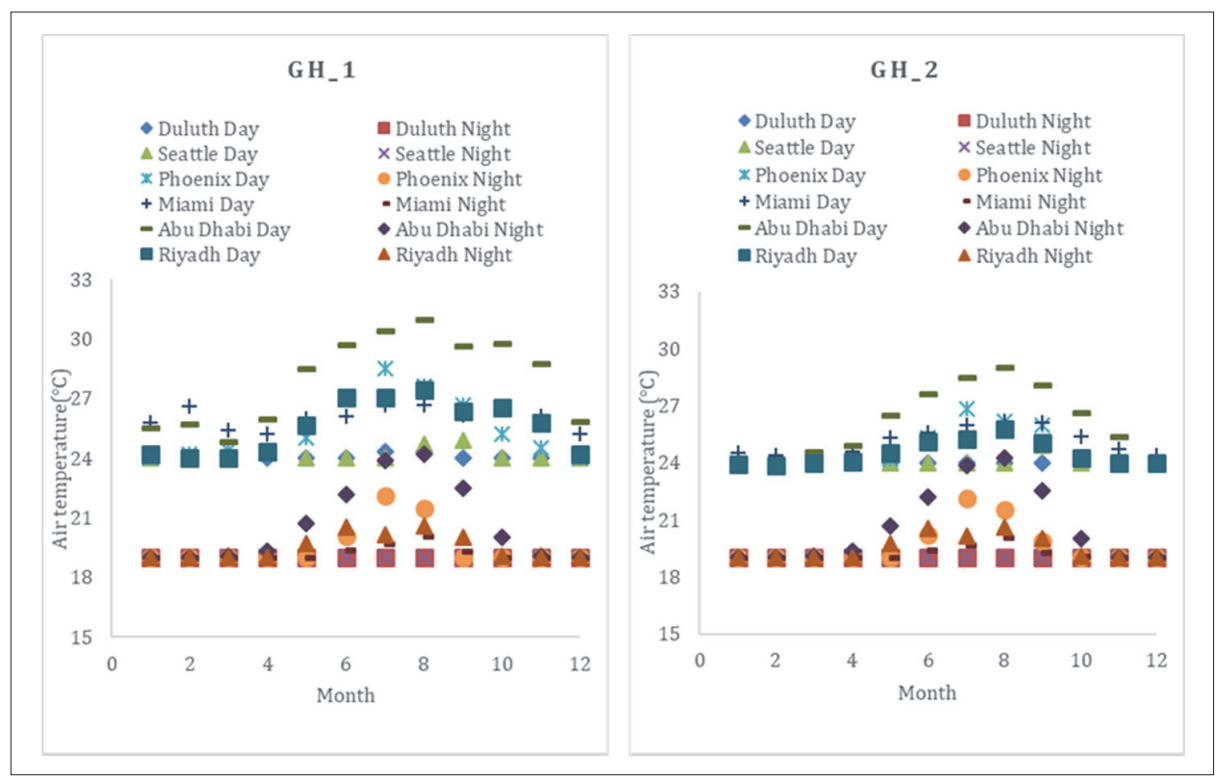

FIGURE 2. Monthly average daytime air temperatures and nighttime air temperatures inside Greenhouse 1 (GH_1) and Greenhouse 2 (GH_2). systems. In the summer season, evaporative cooling system could not meet the demand for cooling, especially for the greenhouses in hot and humid climates. The monthly average daytime and nighttime air temperatures for the two types of greenhouse system are shown in Figure 2. With the DLI control, the air temperatures in Greenhouse 2 (GH_2) are closer to the set points compared to Greenhouse 1 (GH_1), with lower monthly average daytime air temperatures during the summer season in hot climates. The cities in cold climates, Duluth and Seattle, can maintain the set points of air temperature even in the summer season with or without shading controls. Abu Dhabi had the highest average daytime air temperatures and nighttime air temperatures in summer in both cases. In August, it had daytime/nighttime air temperatures of $31 / 24^{\circ} \mathrm{C}$ in $\mathrm{GH}_{-} 1$ and of $29 / 24^{\circ} \mathrm{C}$ in GH_2. The averages of the difference of daytime temperatures between GH_1 and GH_2 at Duluth, Seattle, Phoenix, Miami, Abu Dhabi, and Riyadh were $0,0.10 .7,0.9,1.8$, and $1.1^{\circ} \mathrm{C}$ respectively. 2. Lettuce production. Air temperatures impact a variety of physiological processes. High air temperatures primarily affect the photosynthetic functions and the thylakoid membranes (Salisbury and Ross, 1985). Air temperature ranging from 17 to $28^{\circ} \mathrm{C}$ (daytime) and 3 to $12^{\circ} \mathrm{C}$ (nighttime) was suitable for outdoor lettuce production (Wurr et al., 1992). For the production of lettuce in greenhouses, it was recommended to maintain $24^{\circ} \mathrm{C}$ as the optimal air temperature for daytime operations (Marsh, 1987). From the predicted results, it showed that PAR intensity and air temperature inside the greenhouse affected the growth rates of lettuce. For example, for GH_2 at Duluth, the total days for each harvesting cycle were $34,31,28,26,25,24,24,25,26,28,31$, and 34 from January to December. At Miami, the total days for each harvesting cycle were $32,30,29,28,30,29,31,31,32,31$, and 32 from January to December. The monthly average day time temperature at Duluth was maintained at $24^{\circ} \mathrm{C}$ and at Miami were 24.5, 24.4, 24.3, 24.6, 25.3, 25.6, 26, 26.2, 26.1, $25.4,24.7,24.4^{\circ} \mathrm{C}$ from January to December. With a constant day time temperature and DLI level, GH_2 at Duluth has the shortest growing cycle during the summer season. At these two locations, the average hourly PAR intensity in the summer was higher than it was in the winter as no supplemental lighting required during the summer season. The predicted results from the crop model showed that higher hourly PAR intensity in the summer season increased the growth rate of lettuce. At Miami, during the summer season, although the hourly light intensity is higher, the higher average day time temperature resulted in a slower growth rate of lettuce. The shortest harvesting cycle was found in the spring season. Although the lettuce model considers the effect of high temperatures on the growth rate of lettuce, it cannot quantify how high temperatures change the quality of lettuce. For example, some lettuce can bolt and become bitter when they are growing above $24^{\circ} \mathrm{C}$. Future research on a lettuce growth model under extreme climate conditions is needed to identify changes in both yield and quality. From the predicted results, it was found that Abu Dhabi had the lowest numbers of growing cycles in a year with the highest average air temperatures in GH_1 and GH_2. Duluth achieved the highest production compared to other locations under optimal temperatures. The total number of growing cycles (from transplanting to harvest) for Duluth, Seattle, Phoenix, Miami, Abu Dhabi, and Riyadh were $13,11,13,12,10,13$ respectively in GH_1 and 12, 12,12,11, 10, 12 respectively in GH_2. In the indoor plant factories, air temperatures were assumed to be maintained at set points. The production of lettuce crop under the same level of DLI was the same at all locations. The growing cycles in IPF_1 (DLI=13) was 11 and in IPF_2 (DLI = 15) was 12 .

3. Energy consumption. The yearly energy consumptions were evaluated by the end-use electrical usage over a year for all cases for lighting, heating, and cooling. In greenhouses, the electrical use for cooling was calculated according to the power consumption of exhausted fans and water pumps. The electric usage of heating was computed using the formula: the total heating load divided by the efficiency of heating system $(80 \%)$. Figure 3 shows the yearly energy consumptions in Greenhouse 1 (GH_1), Greenhouse 2 (GH_2), Indoor Plant Factory 1 (IPF_1), and Indoor Plant Factory 2 (IPF_2). In greenhouse cases, heating is the main demand for indoor climate control. In cold climate regions, the energy demands for heating and cooling were doubled or even tripled compared to the greenhouses operating in hot climate regions. Maintaining DLI at $15 \mu \mathrm{mol} \mathrm{m}{ }^{-2} \mathrm{~d}^{-1}$ increased the electricity usage for heating and decreased the cooling demand in GH_2. In indoor plant factory cases, lighting is the major energy consumer. With increased level of DLI from 13 to $15 \mu \mathrm{mol} \mathrm{m}^{-2} \mathrm{~d}^{-1}$, 


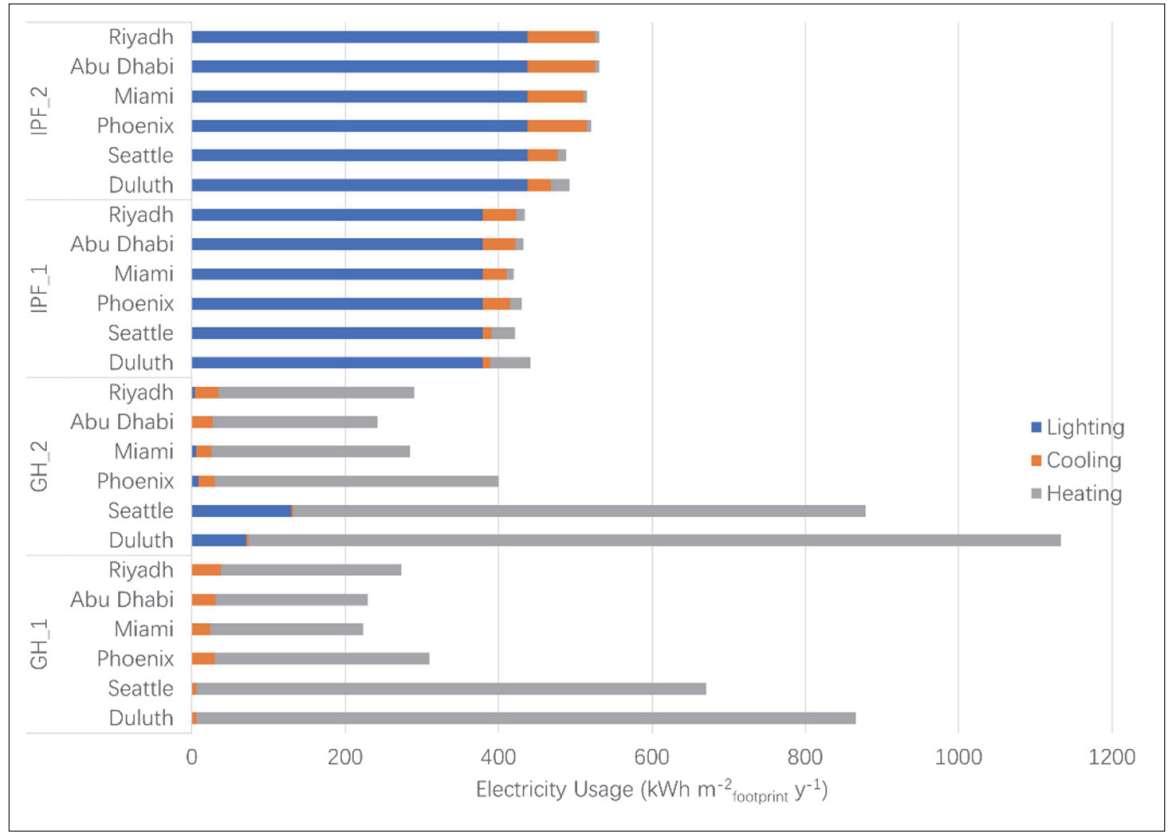

FIGURE 3. Yearly energy consumption of Greenhouses and Indoor Plant Factories for heating, cooling, and heating, normalized for footprint $\left(\mathrm{kWh} \mathrm{m}^{-2}\right.$ footprint $\left.\mathrm{y}^{-1}\right)$. the cooling demands increased while the heating demands decreased. Comparing the total electrical usage at different locations, Miami needs the smallest amount of energy for climate control compared to other locations when DLI was set at $13 \mu \mathrm{mol} \mathrm{m}^{-2} \mathrm{~d}^{-1}$ and Seattle was the best location for energy saving when DLI $=15 \mu \mathrm{mol} \mathrm{m}^{-2} \mathrm{~d}^{-1}$.

4. Energy use efficiency. The energy use efficiency of all studied cases was summarized in Figure 4. In greenhouses, with evaporative cooling, the cooling costs are much lower compared to heating costs when the same amount of energy load needs to be removed or added. Therefore, building greenhouse in hot climate regions can take the advantages of natural sunlight and favorable outdoor climate to reduce heating and lighting costs. The results showed that Miami was the best location for improving energy use efficiency in GH_1 with $0.35 \mathrm{~kg}$ fresh weight of lettuce per kWh electrical usage. When DLI was under control, the average temperatures in Abu Dhabi and Riyadh were reduced and thus the productivity enhanced, which greatly improved the energy use efficiency in extremely hot climate regions. Due to the high energy demand of lighting, indoor plant factories had lower energy efficiency compared to the greenhouses located under hot climate. In cold climate regions, the insufficient solar radiation, a large amount of heat loss, and high heating requirements to maintain the indoor air temperature all re- duce the energy use efficiency in the greenhouses. The IPF_1 and IPF_2 were more efficient for lettuce production than GH_1 and GH_2 in Duluth and Seattle. Compared to IPF_2, IPF_1 with DLI $=13 \mu \mathrm{mol} \mathrm{m}^{-2} \mathrm{~d}^{-1}$ was more efficient. Although IPF_2 sacrificed the production of lettuce, the total electricity cost was also reduced. It resulted in a more efficient energy use in IPF_1.

\section{Parameter studies}

1. Tiers of production system. Besides comparing greenhouses and indoor plant factories for 1-tier production systems, multi-tiers production systems in indoor plant factories were studied to invest how the total levels of production shelves affect the energy consumption and energy use efficiency in indoor plant factories. The electricity usage for lighting, heating, and cooling were compared for Indoor Plant Factory 2 (IPF_2) with 1 tier (IPF_2), 5 tiers (IPF_2 + 5 tiers), and 11 tiers (IPF_2 +11 tiers). The result is shown in Figure 5. With increasing tiers, the electricity demand for lighting and cooling increased while the heating requirements decreased. It could be explained as that the increased internal heat gains reduced the heating requirements and increased cooling loads during the photo period. It was found that the total electricity cost increased linearly with the increase of total tiers of production systems for lighting, cool-

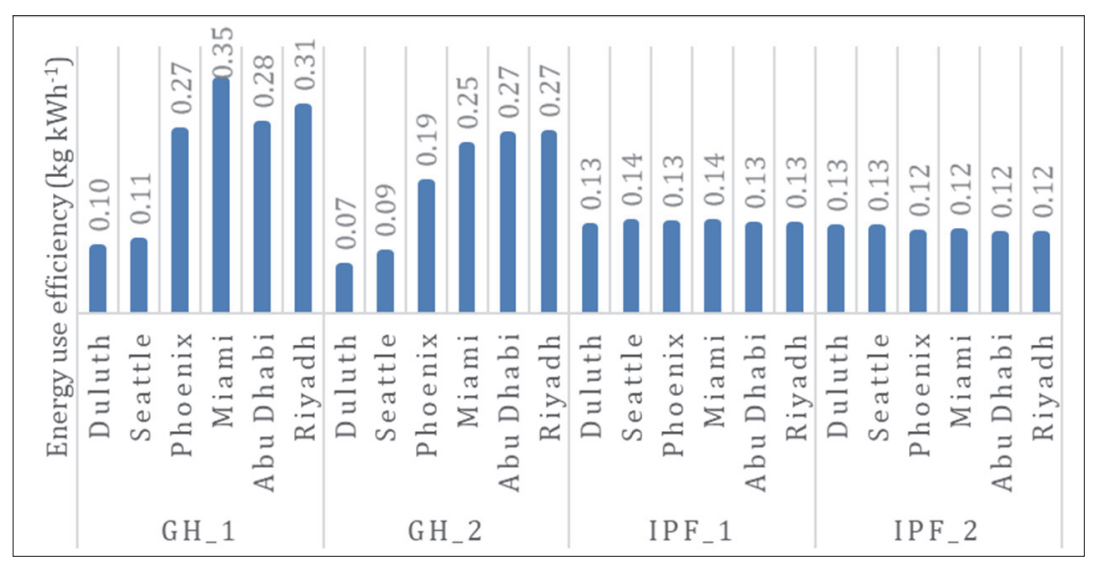

FIGURE 4. The comparison of energy use efficiency in Greenhouses and Indoor Plant Factories. 


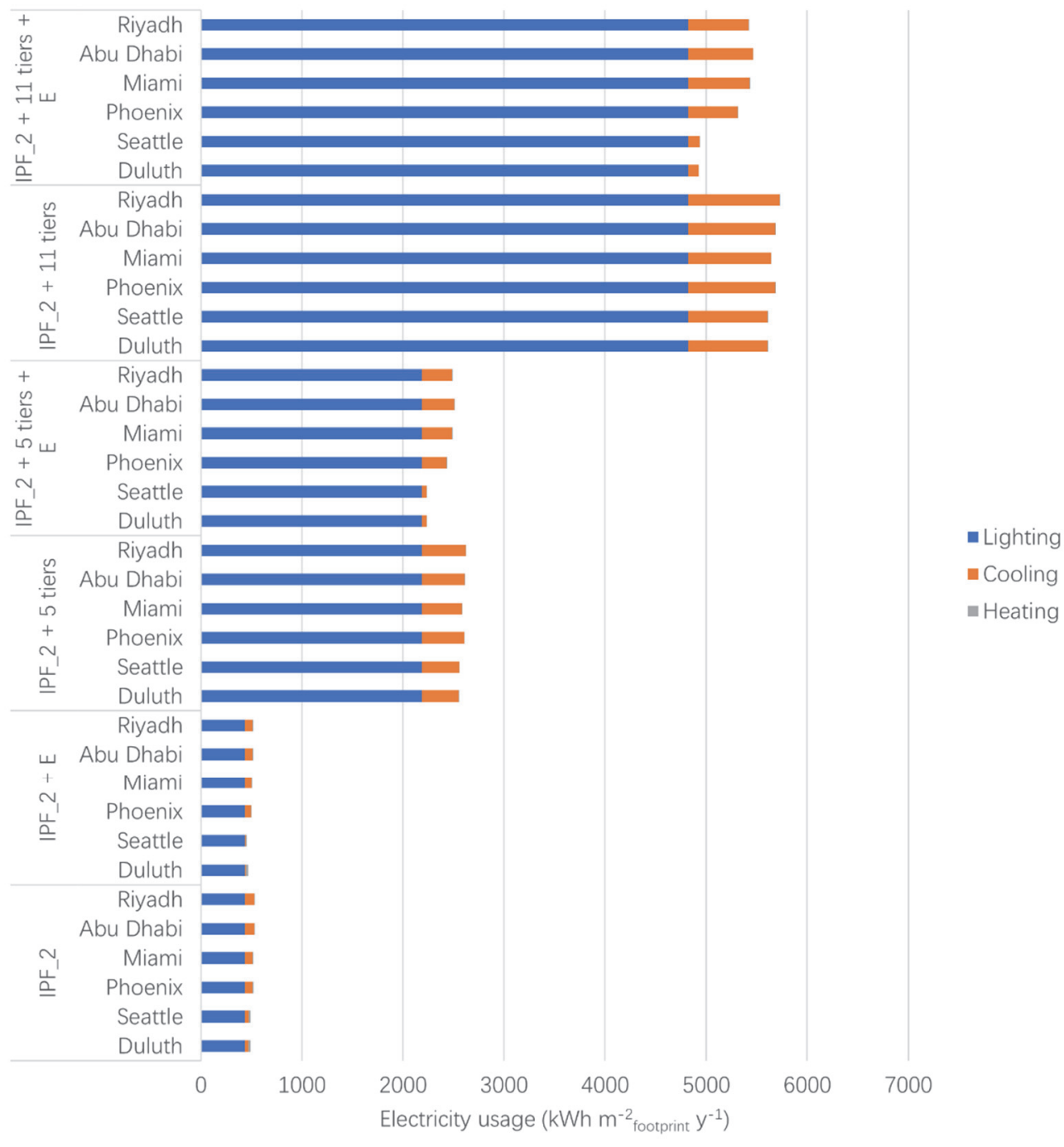

FIGURE 5. The comparison of electrical usage in multi-tier Indoor Plant Factories with Indoor Plant Factory 2 (IPF_2), Indoor Plant Factory 2 with a HVAC economizer (IPF_2 + E), Indoor Plant Factory 2 with 5-tier production shelves (IPF_2 + 5 tiers), Indoor Plant Factory 2 with 5-tier production shelves and a HVAC economizer (IPF_2 + 5 tiers + E), Indoor Plant Factory 2 with 11-tier production shelves (IPF_2 + 11 tiers), and Indoor Plant Factory 2 with 11-tier production shelves and a HVAC economizer (IPF_2 + 11 tiers + E), normalized with footprint.

ing, and heating. For energy use efficiency, only the energy efficiency of case IPF_2 + 5 tiers and case IPF_2 + 11 tiers at Duluth and Seattle decreased slightly from 0.13 to 0.12 $\mathrm{kg} \mathrm{kWh}^{-1}$. Increased tiers did not affect the energy use efficiency of IPF_2 with 5 tiers (IPF_2 + 5 tiers) and 11 tiers (IPF_2 + 11 tiers) at the rest four locations (Phoenix, Miami, Abu Dhabi, and Riyadh). It can be concluded that the tiers of the production system have minimal impact on energy use efficiency for multi-tier indoor plant factories.

2. Economizers. Economizer is a device that can be integrated with HVAC system for commercial buildings. It allows to use outdoor air for cooling when the temperature and humidity of the exterior air is below a certain level. Without the use of energy required to run a compressor, integrating an economizer in the HVAC system in an indoor plant factory can partially or completely remove the cooling load and result in energy saving. In this study, an economizer was integrated in the HVAC system with differential enthalpy economizer control to reduce the energy consumption. Enthalpy is a combined measure of energy that includes both temperature and humidity. The differential enthalpy control means when the enthalpy of the outside air is equal to or lower than the supply air enthalpy, the system shifts to outside air ventilation (Wang, 2001). It is theoretically more efficient than the differential dry-bulb economizer control, especially for locations having hot and humid climates (Lee and Chen, 2013). The energy saving of using an economizer were analyzed for Indoor Plant Factory 2 (IPF_2) with 1-tier, 5-tier, and 11-tier production systems. As the results shown in Figure 5, in the case of IPF_2 + E, the energy saving for heating and cooling were $44 \%, 67 \%, 22 \%, 14 \%, 13 \%$, and $17 \%$ respectively for Duluth, Seattle, Phoenix, Miami, Abu Dhabi, and Riyadh. Duluth and Seattle achieved the highest energy saving due to the lowest average outdoor air temperatures over a year. Since indoor plant factories need to be cooled almost all year around, air-side economizers also helped to save energy in hot climates. With increased tiers, the cooling load increased while the heating load decreased. The ratio of the electrical usage for heating to the electrical usage for heating and cooling changed from $44 \%, 23 \%, 8 \%, 7 \%, 6 \%$, and $6 \%$ respectively at Duluth, Seattle, Phoenix, Miami, Abu Dhabi, and Riyadh to nearly 0 at all locations by adding the tiers from 1 
to 11 . This resulted in more significant energy saving with economizers. The energy saving for cooling at Duluth, Seattle, Phoenix, Miami, Abu Dhabi, and Riyadh were $87 \%$, 87\%, $41 \%, 25 \%, 23 \%$, and $30 \%$ separately in IPF +5 tiers $+\mathrm{E}$, and $87 \%, 85 \%, 43 \%, 26 \%, 25 \%$, and $34 \%$ respectively in IPF + 5 tiers + E.

3. Transpiration rates. Plants cool their surrounding air during transpiration. The transpiration effect of plants growing in indoor plant factories changes the portion of sensible cooling loads and heating loads of a HVAC system. To study how sensible cooling loads and heating loads respond to the changes of the transpiration rate of lettuce crop, two cases were compared to the case IPF_2 by increasing and decreasing transpiration rate by $50 \%$, with new transpiration rates of 21.5 and $64.5 \mathrm{~mL}_{\text {head }}^{-1} \mathrm{~d}^{-1}$ respectively.

Figure 6 shows the results of electrical usage in three cases, with the transpiration rate of lettuces at 21.5, 43, $64.5 \mathrm{~mL} \mathrm{head}^{-1} \mathrm{~d}^{-1}$. With lettuces at the lower transpiration rate, less amount of sensible heat was dissipated by plants and converted to the latent heat loads and thereby more en-
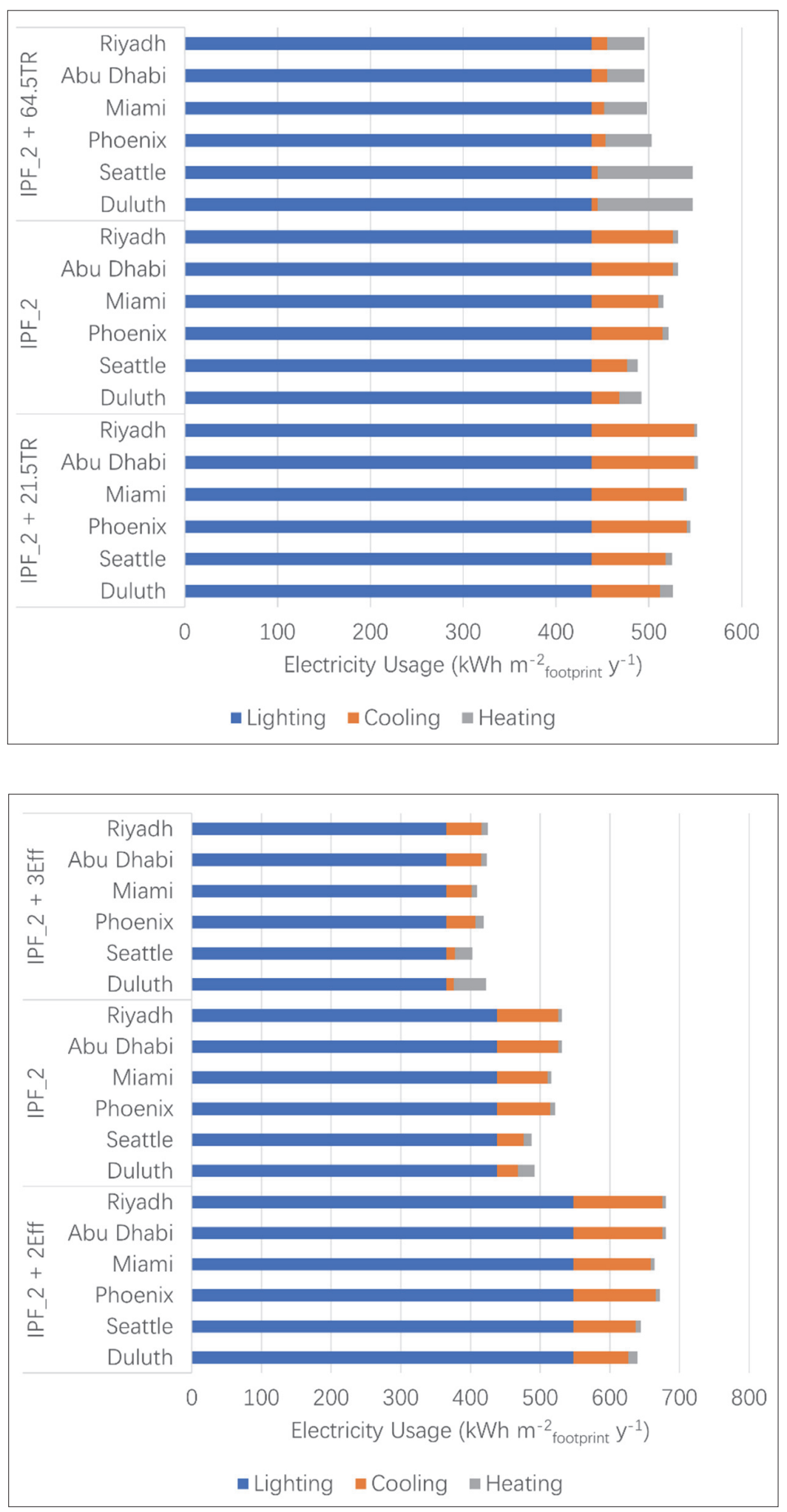

FIGURE 6. Case comparison for transpiration rates at $21.5,43$, and $64.5 \mathrm{~mL} \mathrm{head}^{-1} \mathrm{~d}^{-1}$. 
ergy for cooling is needed to cool the indoor environment. On the contrary, when the transpiration rate was high, sensible cooling loads greatly reduced and converted into latent heat loads. Without humidity controls, the energy need for cooling was reduced and resulted in a large amount of electricity used for heating. As a result of the changes of cooling loads and heating loads, the optimal case changed from IPF_2 at Seattle (IPF_2 + 22.5TR: $488 \mathrm{kWh} \mathrm{m}^{-2}{ }_{\text {footprint }}$ IPF_2: $525 \mathrm{kWh}$ $\mathrm{m}^{-2}$ footprint $)$ to Abu Dhabi with IPF_2 + 64.5TR (496 $\mathrm{kWh} \mathrm{m}^{-2}$ footprint). If cooling is the dominant energy use, a cold climate is more favorable for operating an indoor plant factory. In contrast, if the heating demands are large, a hot climate is better for energy saving.

4. Light efficacy. Heat gain from lights in indoor plant factories is of significant amount. Only a portion of electrical input of lights is converted into useful light output. Much of the rest is released directly as heat into the space. Light efficacy $\left(\mu \mathrm{mol} \mathrm{\textrm {J } ^ { - 1 }}\right)$ is the ratio between the photosynthetic photon flux (PPF, $\mu \mathrm{mol} \mathrm{s}^{-1}$ ) and the electrical source power (W or J s${ }^{-1}$ ) input. The cost of light emitting diode (LED) technology has been declining and LED growing lights keep improving in efficacy every year (Morgan Pattison et al., 2018). The development of LED technology has been bringing the operating costs down for indoor plant factories to make them more profitable ventures. To evaluate how energy consumption responds to light efficacies, two levels of light efficacy: 2 and 3 $\mu \mathrm{mol} \mathrm{J}{ }^{-1}$ were compared to IPF_2. The result is shown in Figure 7. Lighting is the major consumer of the total electrical cost for lighting, heating, and cooling, therefore significant savings were achieved. Compared to IPF_2, the total electricity usage in IPF_2 + 3Eff reduced by $20 \%$ at Riyadh, Abu Dhabi, and Miami, $21 \%$ at Phoenix, $17 \%$ at Seattle, and $14 \%$ at Duluth. On the contrary, IPF_2 + 2Eff increased by $28 \%$ at Riyadh and Abu Dhabi, 29\% at Miami and Phoenix, 32\% at Seattle, and $30 \%$ at Duluth. The fraction of cooling loads and heating loads also changed with different light efficacies. With the high light efficacy $\left(3 \mu \mathrm{mol} \mathrm{J}{ }^{-1}\right)$, heating demand increased while cooling demand decreased. When changing light efficacy to the lower level $\left(2 \mu \mathrm{mol} \mathrm{J}{ }^{-1}\right)$, indoor plant factories need more electricity for cooling rather than heating. The energy use efficiencies of IPF_2 were increased from $0.13 \mathrm{~kg} \mathrm{kWh}^{-1}$ at Duluth and Seattle and $0.12 \mathrm{~kg} \mathrm{kWh}^{-1}$ at Phoenix, Miami, Abu Dhabi, and Riyadh to $0.15 \mathrm{kWh}^{-1}$ at all locations with $3 \mu \mathrm{mol} \mathrm{J}^{-1}$ light efficacy. Using lights with lower light efficacy $\left(2 \mu \mathrm{mol}^{-1}\right)$, the energy use efficiencies dropped to $0.1 \mathrm{~kg} \mathrm{kWh}^{-1}$ at Duluth and Seattle and $0.09 \mathrm{~kg} \mathrm{kWh}^{-1}$ at Phoenix, Miami, Abu Dhabi, and Riyadh, compared to IPF_2.

\section{Conclusions}

Two greenhouse cases and two indoor plant factory cases were compared in this study with energy use efficiency for lettuce production. The energetic requirements were evaluated as the electricity usage of lighting system and climate management system as lighting, cooling, and heating. The lettuce production in each growing system were predicted with a lettuce growth model in kg fresh weight. In this study, indoor plant factories are superior to greenhouses in cold climates (Duluth and Seattle), while greenhouses are more efficient than indoor plant factories in hot climates (Phoenix, Miami, Abu Dhabi, and Riyadh).

The electricity usage increased linearly with the increased number of tiers of production system. The energy use efficiency remained the same for multi-tier indoor plant factories. Productivity of lettuce per unit area of footprint of an indoor plant factory increased in proportion to the num- ber of tiers. Potential strategies for energy savings for indoor plant factories were integrating economizers to HVAC system and installing LED lights with a high light efficacy. An HVAC Economizer can save up to $87 \%$ of electricity usage for cooing in cold climates (Duluth and Seattle) while the energy saving in hot climate is less significant (around 30\%) but is still considerable. The cold and dry outdoor climate is ideal for an economizer with differential enthalpy control. Lighting is the major consumer of energy consumption in indoor plant factories, therefore choosing LED lights with the highest efficacy is the best method to reduce the electricity usage and to enhance energy use efficiency for indoor plant factories.

\section{References}

Both, A. (2003). Ten years of hydroponic lettuce research. https:// www.researchgate.net/publication/266453402_TEN_YEARS_OF_ HYDROPONIC_LETTUCE_RESEARCH.

Boulard, T., and Wang, S. (2002). Experimental and numerical studies on the heterogeneity of crop transpiration in a plastic tunnel. Comput. Electron. Agric. 34, 173-190. https://doi.org/10.1016/ S0168-1699(01)00186-7.

Defraeye, T., Verboven, P., Ho, Q.T., and Nicolai, B. (2013). Convective heat and mass exchange predictions at leaf surfaces: Applications, methods and perspectives. Comput. Electron. Agric. 96, 180-201. https://doi.org/10.1016/j.compag.2013.05.008.

Eaves, J., and Eaves, S. (2018). Comparing the profitability of a greenhouse to a vertical farm in Quebec. Can. J. Agric. Econ. 66, 4354. https://doi.org/10.1111/cjag.12161.

Graamans, L., Baeza, E., Van den Dobbelsteen, A., et al. (2018). Plant factories versus greenhouses: Comparison of resource use efficiency. Agric. Syst. 160, 31-43. https://doi.org/10.1016/j.agsy.2017.11.003.

Graamans, L., Van den Dobbelsteen, A., Meinen, E., and Stanghellini, C. (2017). Plant factories; crop transpiration and energy balance. Agric. Syst. 153, 138-147. https://doi.org/10.1016/j.agsy.2017.01.003.

Gupta, S.K., Ram, J., and Singh, H. (2018). Comparative study of transpiration in cooling effect of tree species in the atmosphere. J. Geosci. Environm. Prot. 6, 151-166. https://doi.org/10.4236/ gep.2018.68011.

Harbick, K., and Albright, L.D. (2016). Comparison of energy consumption: Greenhouses and plant factories. Acta Hortic. 1134, 285-292. https://doi.org/10.17660/ActaHortic.2016.1134.38.

Hosni, M.H., Jones, B.W., and Xu, H. (1999). Experimental results for heat gain and radiant/convective split from equipment in buildings.

Kacira, M., Jensen, M., Robie, T., Tollefson, S., and Giacomelli, G. (2017). Use resources wisely: Waste management and organic liquid fertilizer use in greenhouse production system. Acta Hortic. 1164, 541-548. https://doi.org/10.17660/ActaHortic.2017.1164.71.

Kalantari, F., Tahir, O.M., Joni, R.A., and Fatemi, E. (2018). Opportunities and challenges in sustainability of vertical farming: A review. J. Landsc. Ecol. Rep. 11, 35-60. https://doi.org/10.1515/ jlecol-2017-0016.

Lee, K.P., and Chen, H.L. (2013). Analysis of energy saving potential of air-side free cooling for data centers in worldwide climate zones. Energy Build. 64, 103-112. https://doi.org/10.1016/j. enbuild.2013.04.013.

Liu, R., Zhou, X., Lochhead, S.J., et al. (2017). Low-energy LED lighting heat gain distribution in buildings, part II: LED luminaire selection and test results. Sci. Technol. Built. Environm. 23, 688-708. https:// doi.org/10.1080/23744731.2016.1250563. 
Marsh, L.S. (1987). A model of greenhouse hydroponic lettuce production: Daily selection of optimum air temperatures and comparison of greenhouse covers. Cornell University.

Mesmoudi, K., Soudani, A., and Bournet, P. (2010). Determination of the inside air temperature of a greenhouse with tomato crop under hot and arid climates. J. Appl. Sci. Environm. Sanit. 5, 117-129.

Morgan Pattison, P., Hansen, M., and Tsao, J.Y. (2018). LED lighting efficacy: Status and directions. Comptes Rendus Phys. 19, 134-145. https://doi.org/10.1016/j.crhy.2017.10.013.

Okada, K., Yehia, I., Teitel, M., and Kacira, M. (2018). Crop production and energy generation in a greenhouse integrated with semitransparent organic photovoltaic film. Acta Hortic. 1227, 231-239. https://doi.org/10.17660/ActaHortic.2018.1227.28.

Pearson, S., Wheeler, T.R., Hadley, P., and Wheldon, A.E. (1997). A validated model to predict the effects of environment on the growth of lettuce (Lactuca sativa L.): Implications for climate change. J. Hortic. Sci. 72(4), 503-517. https://doi.org/10.1080/14620316.1 997.11515538.

Pollet, S., Bleyaert, P., and Lemeur, R. (2000). Application of the Penman-Monteith model to calculate the evapotranspiration of head lettuce (Lactuca sativa L. var. capitata) in glasshouse conditions. Acta Hortic. 519, 151-161. https://doi.org/10.17660/ actahortic.2000.519.15.

Salisbury, F.B., and Ross, C.W. (1985). Plant Physiology (Wadsworth Publishing Company).

Sanford, S. (2009). Reducing Greenhouse Energy Consumption - An Overview (A3907-01), p. 1-16.

Shimizu, H., Kushida, M., and Fujinuma, W. (2008). A growth model for leaf lettuce under greenhouse environments. Environm. Control Biol. 46, 211-219. https://doi.org/10.2525/ecb.46.211.

Van Henten, E.J. (1994). Validation of a dynamic lettuce growth model for greenhouse climate control. Agric. Syst. 45, 55-72. https:// doi.org/10.1016/S0308-521X(94)90280-1.

Wang, S.K. (2001). Handbook of Air Conditioning and Refrigeration, $2^{\text {nd }}$ edn. (New York, USA: McGraw-Hill Comp., Inc.).

Wurr, D.C.E., Fellows, J.R., and Hambidge, A.J. (1992). Environmental factors influencing head density and diameter of crisp lettuce cv. Saladin. J. Hortic. Sci. 67, 395-401. https://doi.org/10.1080/00221 589.1992 .11516264$.

Received: Apr. 12, 2020

Accepted: Jul. 24, 2020

Address of authors:

Ying Zhang and M. Kacira*

Department of Biosystems Engineering, The University of Arizona, Tucson, USA

* Corresponding author;

E-mail: mkacira@arizona.edu; Tel.: +1(520)-626-4254 
International Workshop on Vertical Farming

13-15 October 2019

Wageningen, The Netherlands

Sponsored by
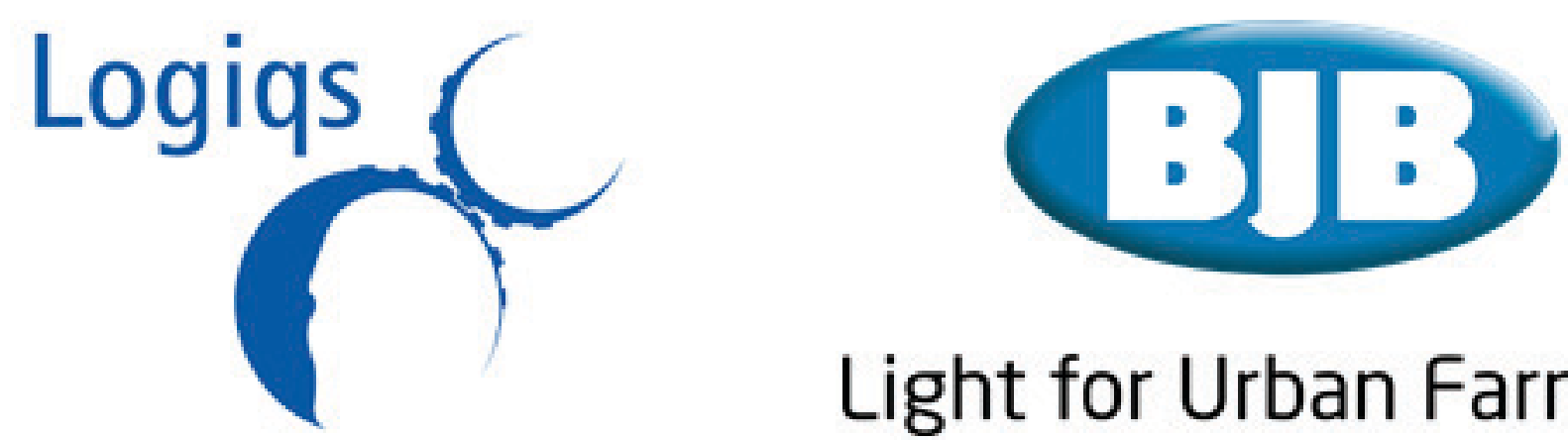

\section{Light for Urban Farming}

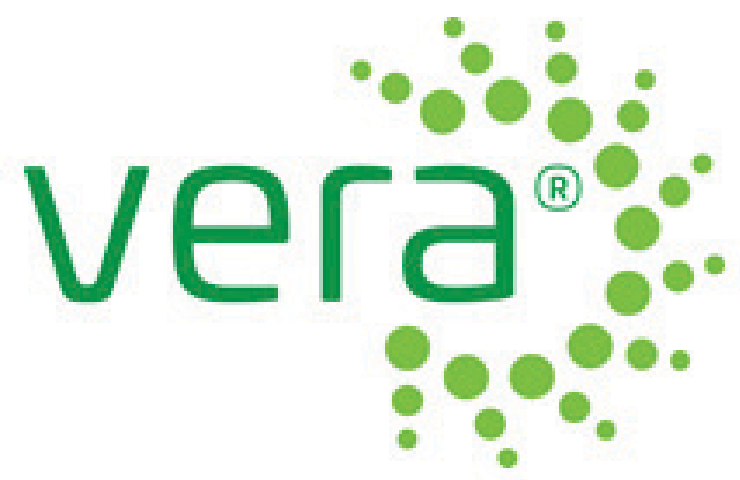

Nouryon

\section{Chelated} Micronutrients
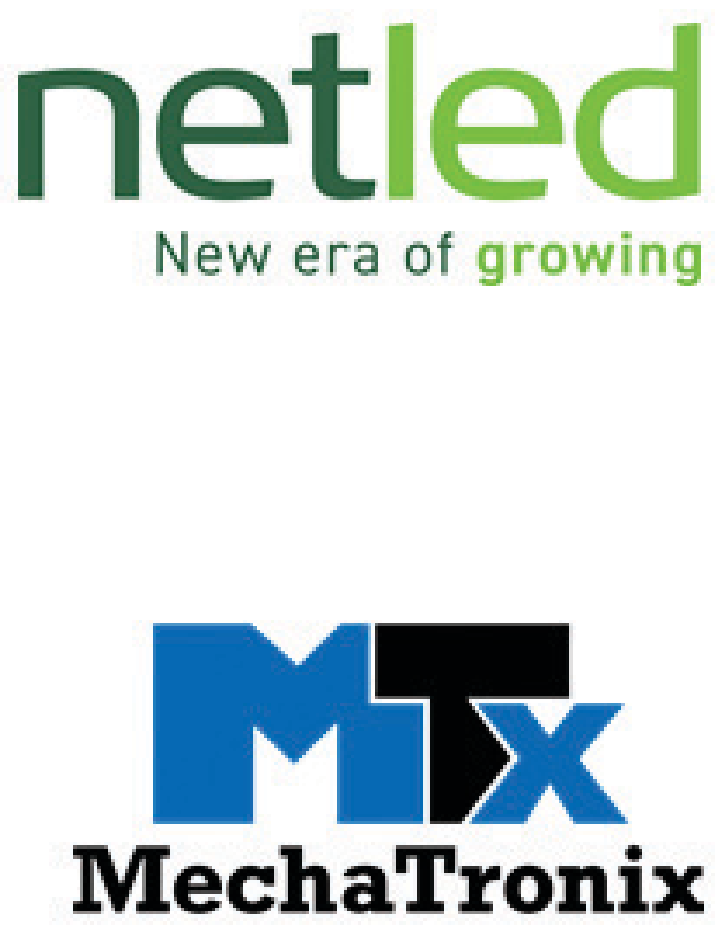

Fடㅁㅁய

$$
\text { F L U E N C E }
$$

